Article

\title{
Comparing Annoyance Potency Assessments for Odors from Different Livestock Animals
}

\author{
Hanns Moshammer ${ }^{1}\left(\mathbb{D}\right.$, Dietmar Oettl $^{2}$, Michael Mandl ${ }^{3} \mathbb{D}$, Michael Kropsch $^{4}$ and \\ Lisbeth Weitensfelder 1 ,* \\ 1 Department of Environmental Health, Center for Public Health, Medical University of Vienna, \\ 1090 Vienna, Austria; hanns.moshammer@meduniwien.ac.at \\ 2 Air Quality Control, Government of Styria, 8010 Graz, Austria; dietmar.oettl@stmk.gv.at \\ 3 Department Chemistry and Environment, Government of Salzburg, 5020 Salzburg, Austria; \\ michael.mandl@salzburg.gv.at \\ 4 Agricultural Research and Education Centre Raumberg-Gumpenstein, 8952 Irdning-Donnersbachtal, \\ Austria; michael.kropsch@raumberg-gumpenstein.at \\ * Correspondence: lisbeth.weitensfelder@meduniwien.ac.at; Tel.: +43-1-40160-34911
}

Received: 25 September 2019; Accepted: 25 October 2019; Published: 29 October 2019

\begin{abstract}
Background: When it comes to estimating the annoyance potency of odors, European countries relate to different guidelines. In a previous study we compared complaint rates for different agricultural odors, but due to different guidelines, the results we obtained are hard to generalize. (2) Methods: We compare our findings on complaint rates to Dutch and German findings on annoyance rates, using diverse regression models. We also discuss whether the use of the polarity profile for hedonic odor quality could improve annoyance potency assessment. This is demonstrated by comparing the graphical profiles of two different odor types (swine and cattle). (3) Results: Official complaint rates are comparable to a percentage of annoyed residents. Confounder variables such as personal variables do not greatly contribute to annoyance. However, individual emission sites also showed an important influence on complaints and hence on annoyance. Considering the hedonic quality of odors via the polarity profile method for improving an annoyance potency assessment cannot be recommended when using the given state of the method. This is particularly true when it comes to the rating of specific odors, as the method then seems to lack reliability. (4) Conclusions: Where data on annoyance rates are lacking, complaint data could be used instead.
\end{abstract}

Keywords: odor annoyance; annoyance potency; odor guidelines; odor frequency; hedonic odor quality

\section{Introduction}

Freeman and Cudmore [1] suggested that five factors determine annoyance due to odors: frequency $(\mathrm{F})$, intensity $(\mathrm{I})$, duration (D), offensiveness $(\mathrm{O})$, and location $(\mathrm{L})$, such as when considering differences between living, rural or industrial areas. Their concept, coined as FIDOL, was later endorsed and embraced by others [2-4]. But usually odors are assessed in the living area. As such, the fifth aspect, location, can be considered as a constant. Different characteristics of the living area may play a role, but are hard to quantify. We have shown that administrative zoning rules in the Austrian context are not sensitive enough to serve as predictors for complaint rates and thus of annoyance [5].

The first three factors are all quantitative measures of exposure and therefore likely to be highly correlated with each other: If the average odor concentration at a given place is high, then the odor threshold is also likely to be exceeded more frequently $(\mathrm{F})$, the peak concentrations will be higher (I), and the exceedances will last longer (D). Therefore, both in the regulatory setting and in field research, it is usually neither possible nor necessary to include all three factors in one model. 
In this paper, the focus is on offensiveness. We will compare findings and rules regarding the offensiveness of three different odors (animal husbandry of pigs, cattle, and poultry) that are widespread and therefore have been studied repeatedly and are covered by rules and regulations. We will compare our own findings regarding complaint rates [5] with other studies from Germany [6-8] and the Netherlands $[9,10]$ regarding percentage of highly annoyed persons. We will further compare the results with weighting factors applied in German and Austrian regulations for environmental odors [11,12].

Guidelines in Austria and Germany differ from other European guidelines since they use percentages of odor hours (F) instead of other measures such as percentiles of concentration (I). For Austria, no comprehensive common guideline exists yet, although a new guideline was recently issued for the regions of Styria and Salzburg [12,13]. Hence, Austrians often refer to the German Guideline on Odour in Ambient Air (GOAA) [11], where-depending on the location (residential, industrial)—between $10 \%$ and $15 \%$ of odor hours are defined as thresholds of acceptability. Accounting for different annoyance potency, GOAA uses weighting factors for the three types of animals considered in this study.

Here we will examine more closely the offensiveness of these three types of odors as models for other types of odor as well: Knowing from field studies that the offensiveness differs by animal type, we will try to quantify that difference and examine if this difference can also be captured by panel ratings. If this is the case, then it might aid in improving the assessment of offensiveness of other odors that are either new, little known, or not studied yet. More specifically, we will compare our findings on relative offensiveness of the three odors to the ratings of qualified panelists following the polarity-profile approach [14,15].

Rating impressions on a polarity profile roots back to the method of the semantic differential developed in the 1950s [16]. The application in the context of odors has been tried for numerous purposes, e.g., for general scientific research [17] or for consumer research [18]. But the polarity profile method has also been used successfully in the context of annoyance [15]. As opposed to a rating scheme based simply on the pleasantness vs. unpleasantness of odors, three basic dimensions prevail in the semantic room: Evaluation (pleasantness), potency (strength), and activity (arousal). The polar adjectives used in the semantic differential can be either pure or more oblique in representing one or several of the basic dimensions [17], but either way a polarity profile provides a more detailed definition than "just" the hedonic quality. The use of polarity profiles for odor assessment in ambient air is regulated in a German VDI (Verein Deutscher Ingenieure) guideline [19]: Trained panel members assess the hedonic quality of odors based on 29 polar adjectives (e.g., "harmonious-disharmonious") using a seven-point rating scale. The method, which focuses on the subjective rating of assessors, can be seen overall as valid [14], even though the reliability is higher if the assessment does not happen on a seven-point rating scale-as it is used in the VDI guideline-but a three-point scale instead. In the case of a three-point scale, assessors determine whether an odor is harmonious or disharmonious (or none of it), but there is no further quantification. That takes different rating tendencies of individuals into account, with some tending more to extremes than others. With this restricted scale, it is only possible to classify odors as either stench or smell but a more detailed sub-division of annoying odors into different categories is not possible. Regarding the sample size, it has been shown that eight assessors are sufficient to gain statistically stable profiles [14].

Of course, not all ratings regarding annoyance potency are based on polarity profiles: A new method suggests evaluating acceptability on a single 11-categorical scale (from very unpleasant to very pleasant) for several dilution levels and extrapolating the acceptability for dilution levels from $-\infty$ to $+\infty$. The actual annoyance potential could then be calculated by multiplying acceptability with odor concentration [20,21]. The idea of considering concentration seems plausible, but not much research exists yet evaluating the latter approach. Including duration and/or frequency of odor concentration levels would be quite challenging in this approach, making it hardly applicable in a current regulatory setting. 
Hence, the present research aims to compare annoyance with complaint rates and to evaluate whether panelist ratings using a polarity profile can predict differences in offensiveness as observed in field studies.

\section{Experiments}

\subsection{Own Data}

In our recent study [5], we have linked odor frequency caused by swine, fowl, animal-bowel cleanse for sausage production, and compost works, to the likelihood of complaints filed by residents with governmental agencies. Here we focus on odors from swine and fowl husbandry, because we can compare our complaint data to the percentage of highly annoyed residents from other studies $[6,10]$. For that aim, we have added data from additional farms with pig and fowl husbandry to our data. We have also used updated default emission factors for swine and fowl. Usually in Germany and Austria emission values (odor units per second and per animal mass for several types of animals) are applied as proposed by the German standard VDI 3894-1 [22]. We applied these emission factors in our previous study to demonstrate how many complaints are to be expected when new enterprises are approved based on standard procedures. For comparing our results with those of other studies, we had to use comparable exposure estimates. The German studies [6-8] used field inspections [23] to assess exposure, and therefore, no uncertainties were introduced arising from modeling odor hours using emission factors and dispersion models. A comprehensive literature study [24-26] and our own olfactometric measurements at pig and fowl sheds $[27,28]$ demonstrated that VDI 3894-1 default values [22] substantially underestimate real emissions for these animals. Consequently, also odor frequencies would be underestimated. Therefore, we used more plausible emission factors in our present study as recommended in Oettl et al. [29]. A Dutch study used later in this work [9] applied an emission factor for fattening pigs similar to the one as recommended in Oettl et al. [29] for their exposure models.

To compare our dose-response curves regarding complaints with the German and Dutch dose-response curves examining annoyance, we applied the methodology established in our previous study: Exposures at each residency were estimated using the Lagrangian particle model GRAL [30] for assessing odor hours at the residents' address. It has been demonstrated [27] that in the Alpine geographical and meteorological setting, this model provides odor frequencies in accordance with results from field inspections [31], which provided the input of correct emission data.

Exposure and complaint data were handled in a way that has proved to be the best one in our previous study [5]: In a first step, percent odor hours $(\% \mathrm{OH})$ were $\log$ transformed $(\log (1+\% \mathrm{OH}))$. To allow a direct comparison with a German study [6,7], we performed a binary log (lb) transformation. Next a logistic regression was run, investigating the effect of $\log (1+\% \mathrm{OH})$ and odor type (fowl compared to swine) on likelihood of complaints. Although we have demonstrated that odor-hour frequencies during day-time provide a slightly better model fit than total ( $24 \mathrm{~h}$-) odor-hour frequencies, for reasons of comparability with the German studies, we restricted this analysis to total odor-hour frequencies. We also ran models for swine and fowl odor separately. To study in greater detail the effect of the individual farm (since complaining or non-complaining neighbors cluster around specific farms), we ran generalized estimating equations defining "farm" as panel variable (STATA command "xtgee", family: binomial, link: logit) for swine and fowl odor, for which the data set contained enough farms.

To allow comparison with a Dutch study, we also ran a logistic model for the swine odors using the odor concentration at the 98th percentile as independent variable (C98): While Austrian and German guidelines base on $\% \mathrm{OH}$, Dutch guidelines use $\mathrm{C} 98$, where the threshold value (which depends on the offensiveness) is allowed to be exceeded for up to $2 \%$ of total hours during a year. We also visually examined (scatterplots of $\% \mathrm{OH}$ values against percentile data) how percent odor hours and concentration at the 98 th percentile are associated with each other. 


\subsection{Comparison with Other Studies and with Guidelines}

In order to examine whether reported annoyance and likelihood of complaints display similar dose-response functions, we compared our data based on complaints with other studies [6-10] examining reported annoyance. To that end we applied similar models (e.g., binary log transformation) when comparing our data to the Sucker et al. study [6]. Annoyance and complaint findings are compared in tables presenting coefficients for the percentages of households filing complaints, of persons being either annoyed or highly annoyed from the different odor sources.

\subsection{Expert Assessment of Offensiveness}

Fulfilling the necessary amount of eight assessors per profile [14], we collected expert data for 29 pairs of semantic differentials for cattle (livestock building) and swine (pig fattening) in an incomplete design from 9 assessors, with different 8 of them rating each odor. All assessors met the qualification criteria (classification of stench and smell) according to the guideline VDI 3940-4 [19]. The ratings were carried out in December 2018.

Since previous research [14] showed that Fleiss' Kappa coefficients are much better if the polarity profile is rated only three-categorical, we compared our data with the data of the previous study for both the seven-categorical as well as the three-categorical polarity approach.

\section{Results}

\subsection{Exposure Markers}

The final data set consists of 296 neighbors of 17 pig farms, 82 neighbors of six poultry farms, 121 neighbors of 27 composting facilities (using only data from organic waste composting plants), 99 neighbors of nine composting facilities utilizing sludge, and 13 neighbors around a single bowel-cleanse factory.

To allow a comparison with the Dutch study [9], dealing with neighbors of pig farms, not only percent odor hours $(\% \mathrm{OH})$ were calculated but also the odor concentration (in $\mathrm{OU} / \mathrm{m}^{3}$ ) at the 98th percentile (C98) again using the dispersion model GRAL. Scatterplots revealed rather a non-linear association between both markers, with only a fractional difference between a non-linear and linear association (Figure 1). The strongest linear correlation (with an $\mathrm{R}^{2}>0.8$ ) was evident (Table 1 ) after $\log$ transformation of \%OH and logistic transformation of $\mathrm{C} 98(\exp (\mathrm{C} 98) /(1+\exp (\mathrm{C} 98))$.

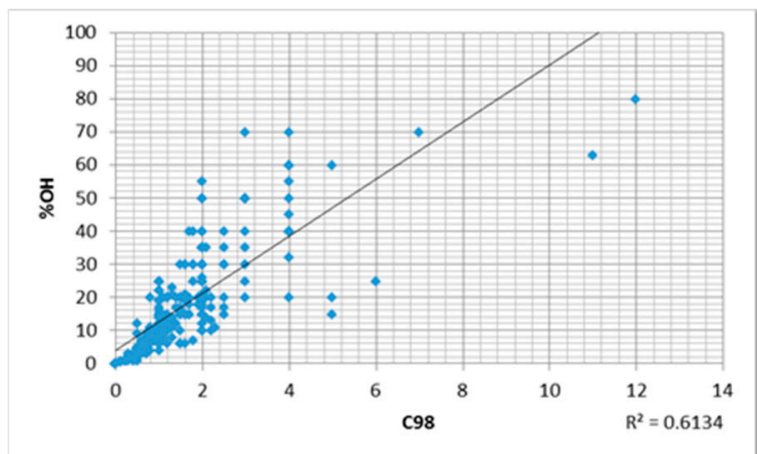

(a)

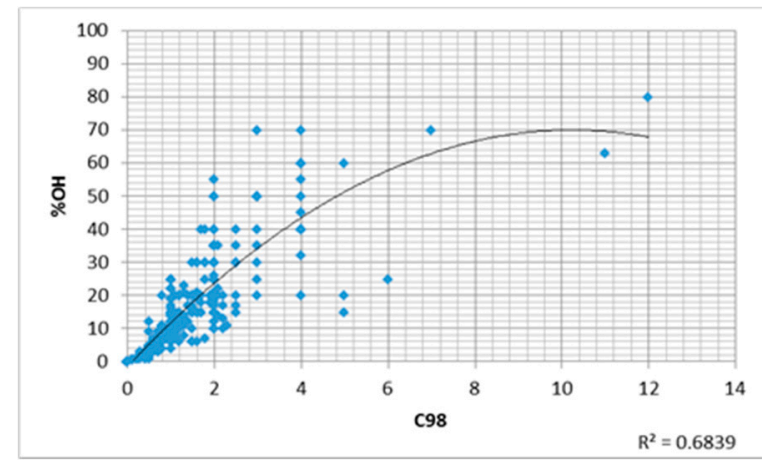

(b)

Figure 1. The association between odor frequency (\% odor hours, $y$-axis) and odor concentration at the 98th percentile (x-axis) was first examined in an Excel scatterplot. A linear association (a) provided a fairly good model fit $\left(R^{2}=0.6134\right)$, but was mathematically implausible because the percentage of odor hours were more than $100 \%$ above reasonably high exposure levels. A polynomial model (b) provided a slightly better fit $\left(R^{2}=0.6839\right)$, but was also implausible as it predicted a decreasing percentage of odor hours above about $10 \mathrm{OU} / \mathrm{m}^{3}$ at the 98 th percentile. Therefore, logistic and logarithmic transformations were tested and are presented in Table 1. 
Table 1. Linear model fit $\left(\mathrm{R}^{2}\right)$ between \% odor hours $(\% \mathrm{OH})$ and concentration at the 98 th percentile (C98) after various transformations.

\begin{tabular}{ccc}
\hline \%OH & $\mathbf{C 9 8}$ & $\mathbf{R}^{\mathbf{2}}$ \\
\hline Raw data & Raw data & 0.6134 \\
Raw data & $\ln (\mathrm{C} 98)$ & 0.5634 \\
Raw data & $\exp (\mathrm{C} 98) /(1+\exp (\mathrm{C} 98))$ & 0.6089 \\
$\ln (\% \mathrm{OH}+1)$ & Raw data & 0.4519 \\
$\ln (\% \mathrm{OH}+1)$ & $\ln (\mathrm{C} 98)$ & 0.5688 \\
$\ln (\% \mathrm{OH}+1)$ & $\exp (\mathrm{C} 98) /(1+\exp (\mathrm{C} 98))$ & 0.8021 \\
$\exp (\% \mathrm{OH}) /(1+\exp (\% \mathrm{OH}))$ & Raw data & 0.6090 \\
$\exp (\% \mathrm{OH}) /(1+\exp (\% \mathrm{OH}))$ & $\ln (\mathrm{C} 98)$ & 0.5679 \\
$\exp (\% \mathrm{OH}) /(1+\exp (\% \mathrm{OH}))$ & $\exp (\mathrm{C} 98) /(1+\exp (\mathrm{C} 98))$ & 0.6175 \\
\hline
\end{tabular}

\subsection{Results of the Logistic Regression}

As already mentioned, swine and poultry data have been added to the data used in our previous study [5], mostly data from farms without complaints. The use of more realistic (higher) emission factors naturally led to higher exposure estimates. Both lower complaint rates and higher exposure estimates, contributed to smaller coefficients than in our previous study. Also, the model fit as measured by the adjusted $\mathrm{R}^{2}$ was weaker. Table 2 reports the results of the logistic regression in the total data set. To allow direct comparison of the coefficients with the German study [6] and our previous study [5] coefficients are reported both for $\log 10(\% \mathrm{OH}+1)$ and for $\mathrm{lb}(\% \mathrm{OH}+1)$.

Table 2. Results of logistic regression: Determinants of complaints.

\begin{tabular}{ccc}
\hline Parameter & Coefficient & $p$-Value \\
\hline Model 1: exposure as $\mathrm{lb}(\% \mathrm{OH}+1)$ & Pseudo $\mathrm{R}^{2}=0.1837$ \\
$\mathrm{Lb}(\% \mathrm{OH}+1)$ & 1.075 & $<0.001$ \\
Swine & 0 & (reference) \\
Poultry & 0.633 & 0.092 \\
Bio-compost & 3.103 & $<0.001$ \\
Sludge-compost & 3.521 & $<0.001$ \\
Bowel cleanse & 3.650 & $<0.001$ \\
Constant & -5.955 & $<0.001$ \\
\hline Model 2: exposure as $\log 10(\% \mathrm{OH}+1)$ & Pseudo $\mathrm{R}^{2}=0.1992$ \\
Log10(\%OH + 1) & 3.829 & $<0.001$ \\
Swine & 0 & $($ reference) \\
Poultry & 0.720 & 0.058 \\
Bio-compost & 3.399 & $<0.001$ \\
Sludge-compost & 3.773 & $<0.001$ \\
Bowel cleanse & 3.911 & $<0.001$ \\
Constant & -6.332 & $<0.001$ \\
\hline
\end{tabular}

Similar logistic regressions conducted for each odor source separately were based on less data points each leading to reduced power, though the findings were generally very similar. Table 3 reports the coefficients for each type of odor source separately for $1 \mathrm{~b}(\% \mathrm{OH}+1)$ and also (for swine only) for C98.

For swine and poultry additional models were assessed that also included a dummy for the farm. Because farms without complaining neighbors were dropped from the model due to collinearity, also the basic models (without dummy for the farm) were restricted to farms with both complaining and not complaining neighbors (Table 4). 
Table 3. Results of logistic regression: Determinants of complaints per type of odor source.

\begin{tabular}{|c|c|c|}
\hline Parameter & Coefficient & $p$-Value \\
\hline \multicolumn{2}{|c|}{ Model 1: swine farms } & Pseudo $R^{2}=0.06$ \\
\hline $\mathrm{Lb}(\% \mathrm{OH}+1)$ & 0.503 & $<0.001$ \\
\hline Constant & -3.471 & $<0.001$ \\
\hline \multicolumn{2}{|c|}{ Model 2: poultry farms } & Pseudo $R^{2}=0.12$ \\
\hline $\mathrm{Lb}(\% \mathrm{OH}+1)$ & 0.979 & 0.012 \\
\hline Constant & -4.967 & 0.001 \\
\hline \multicolumn{2}{|c|}{ Model 3: bio-compost } & Pseudo $R^{2}=0.49$ \\
\hline $\mathrm{Lb}(\% \mathrm{OH}+1)$ & 3.501 & $<0.001$ \\
\hline Constant & -5.453 & $<0.001$ \\
\hline \multicolumn{2}{|c|}{ Model 4: sludge-compost } & Pseudo $\mathrm{R}^{2}=0.49$ \\
\hline $\mathrm{Lb}(\% \mathrm{OH}+1)$ & 2.489 & $<0.001$ \\
\hline Constant & -4.726 & $<0.001$ \\
\hline \multicolumn{2}{|c|}{ Model 5: bowel cleanse } & Pseudo $R^{2}=0.66$ \\
\hline $\mathrm{Lb}(\% \mathrm{OH}+1)$ & 6.951 & 0.172 \\
\hline Constant & -12.30 & 0.179 \\
\hline \multicolumn{2}{|c|}{ Model 6a: swine farms } & Pseudo $R^{2}=0.05$ \\
\hline C98 & 0.396 & 0.001 \\
\hline Constant & -2.171 & $<0.001$ \\
\hline \multicolumn{2}{|c|}{ Model 6b: swine farms } & Pseudo $R^{2}=0.08$ \\
\hline $\operatorname{Ln}(C 98+0,1)$ & 1.061 & $<0.001$ \\
\hline Constant & -1.923 & $<0.001$ \\
\hline
\end{tabular}

Table 4. Alternative logistic regression models: Impact of individual farm.

\begin{tabular}{|c|c|c|}
\hline Parameter & Coefficient & $p$-Value \\
\hline \multicolumn{3}{|c|}{ Swine Farms: 235 neighbors, 12 farms } \\
\hline \multicolumn{2}{|c|}{ Model 1: exposure only } & \multirow{2}{*}{$\begin{array}{l}\text { Pseudo } R^{2}=0.035 \\
0.005\end{array}$} \\
\hline $\mathrm{Lb}(\% \mathrm{OH}+1)$ & 0.410 & \\
\hline Constant & -2.860 & $<0.001$ \\
\hline \multicolumn{2}{|c|}{ Model 2: control for farm } & Pseudo $\mathrm{R}^{2}=0.248$ \\
\hline $\mathrm{Lb}(\% \mathrm{OH}+1)$ & 0.558 & 0.006 \\
\hline Constant & -2.572 & 0.015 \\
\hline \multicolumn{3}{|c|}{ Poultry farms: 62 neighbors, 3 farms } \\
\hline \multicolumn{2}{|c|}{ Model 1: exposure only } & Pseudo $R^{2}=0.066$ \\
\hline $\mathrm{Lb}(\% \mathrm{OH}+1)$ & 0.934 & 0.054 \\
\hline Constant & -4.661 & 0.010 \\
\hline \multicolumn{2}{|c|}{ Model 2: control for farm } & Pseudo $R^{2}=0.091$ \\
\hline $\mathrm{Lb}(\% \mathrm{OH}+1)$ & 1.093 & 0.073 \\
\hline Constant & -5.701 & 0.021 \\
\hline
\end{tabular}

\subsection{Comparison with Other Studies}

In the German study [6] results of a logistic regression on annoyed and on highly annoyed people were reported for emissions from swine, poultry, and cattle farms. Exposure was modeled as in our study as $\mathrm{lb}(\% \mathrm{OH}+1)$. Coefficients are therefore directly comparable (Table 5), whereas complaints are available for swine and poultry farms. Regarding cattle, so far no complaints have been handed in, although thousands of cattle farms can be found in Styria. Reasons could be seen in the lower annoyance potency of cattle odors, as it has also been reported in the German study [6], with several possible causes (e.g., the amount of sulfuric odor compounds or animal density in the farms) which itself could be a topic for additional research. Due to the lack of complaints, coefficients for cattle odors cannot be established from our data, but it can safely be argued that coefficients would be rather 
small. Therefore, no quantitative comparison is possible with the German findings in this regard, but it should be noted that the German effect estimates for cattle were also small and not significantly different from null.

Table 5. Comparison of study results: First part: Coefficients for highly annoyed (\%HA) and from annoyed (\%A) from the German study [6] and for complaints (\%C) from our study. Second part: percentages of (highly) annoyed/complaints are calculated for $10 \%$ odor hours.

\begin{tabular}{cccc}
\hline Parameter & \%A & \%HA & \%C \\
\hline $\mathrm{lb}(\% \mathrm{OH}+1)$ swine & 0.322 & 0.450 & 0.503 \\
$\mathrm{lb}(\% \mathrm{OH}+1)$ poultry & 0.410 & 0.873 & 0.979 \\
$\mathrm{lb}(\% \mathrm{OH}+1)$ cattle & 0.042 & 0.166 & - \\
\hline$\%$ at $10 \%$ OH swine & $35 \%$ & $10 \%$ & $15 \%$ \\
$\%$ at $10 \%$ OH poultry & $50 \%$ & $34 \%$ & $33 \%$ \\
$\%$ at $10 \%$ OH cattle & $19 \%$ & $4 \%$ & - \\
\hline
\end{tabular}

Boers et al. [10] have investigated "livestock farming" odors mainly originating from pig farms. They assessed the impact of $\ln (98$ th percentile +0.1$)$ on "annoyed" in logistic regression in multiple models controlling for different individual parameters. Table 6 compares our results from pig farms with their simplest model. The model fit for this exposure indicator in our data was comparable or even better than for odor frequency (pseudo $\mathrm{R}^{2}=0.079$, Pearson's goodness of fit $p=0.97$, Hosmer-Lemeshow goodness of fit $p=0.67$ ) and better than for the raw 98th percentile data (pseudo $\mathrm{R}^{2}=0.052$, Pearson's goodness of fit $p=0.61$, Hosmer-Lemeshow goodness of fit $p=0.35$ ).

Table 6. Comparison of study results: Coefficients for annoyed (\%A) from the Dutch study [10] and for Complaints $(\% \mathrm{C})$ from our study.

\begin{tabular}{ccc}
\hline Parameter & $\mathbf{\% A}^{\mathbf{a}}$ & $\mathbf{\% C}$ \\
\hline Ln (98th percentile + 0.1) & $0.63 ; 0.79$ & 1.06 \\
Constant & $-4.09 ;-1.77$ & -1.92 \\
\hline
\end{tabular}

Notes: a Boers et al. [10] report results from univariate and from multiple regression models and for "livestock housing" as well as for "lifestock farming". The latter models consider a combination of housing and the spreading of slurry and manure. The range of all estimates is shown in the table.

The effect estimates of Boers et al. [10] for the "livestock housing" only exposure estimates in the simple model only controlling for asthma in the participants are shown in Figure 2 together with our estimates of complaint rates using the same exposure variable (odor concentration at the 98th percentile). We could not provide a similar figure with the German results [6] because the prevalence of the various personal factors included in the models was not reported. In the report [6] also a figure is displayed for highly annoyed people though. From that we can conclude that our results (percentage of complaints per household) are similar and lie in between the percentages of highly annoyed and annoyed people. 


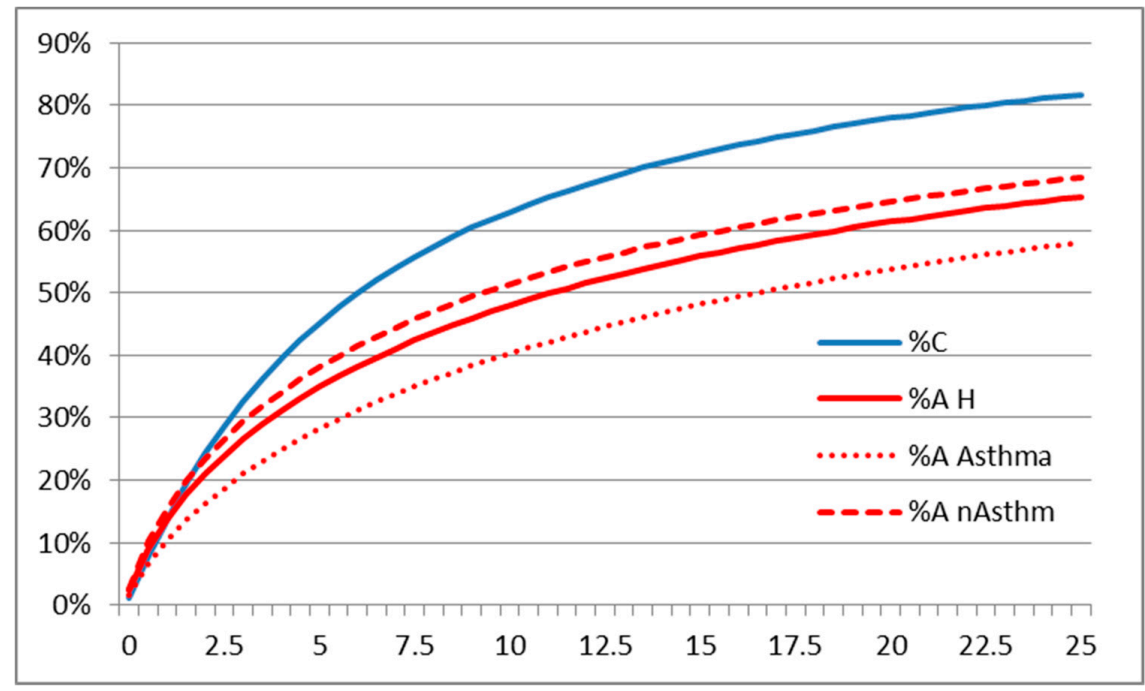

Figure 2. Percentage of complaints (blue, our data) and annoyed persons (red, [10]) per odor units at the 98th percentile. Percentage of annoyed persons reported for asthmatics (dotted line) and not asthmatic respondents (interrupted line) and for the study average (31\% asthmatics, thorough line).

\subsection{Expert Assessment of Offensiveness}

We compared two livestock odors (swine and cattle) using the polarity profile according to VDI 3940-4 [19]. In a first step, assessors filled out the polarity profile by imaging first an extremely unpleasant odor and second an extremely pleasant odor. Those assessors not falling within a defined scope would have to be excluded from the experiments, but all assessors fulfilled the criteria, so the subsequent swine and cattle odor ratings from all assessors could be adducted. The representative curves for smell and stench in Figure 3 were derived by weighting the responses (subjective ratings) of the assessors with the factors according to the VDI guideline [19].

Swine is not as close to a representative stench as cattle, but overall both odors look very similar (Figure 2). A direct comparison of rating a single polar-rating for pleasantness, as it was done in French studies $[20,21]$, is not possible due to the different scaling (7-categorical vs. 11-categorical), but the rating for this polar in our study gives an idea of a rather unpleasant smell which was equally rated for both swine and cattle.

Comparing the Fleiss' Kappa values of different assessors, agreement for cattle and swine odors is basically not existent on a seven-point rating scale, even though the agreement of rating stench and smell generally is comparable with the results obtained in the German study [14]. The agreement for rating cattle and swine odors reaches low to moderate levels when using a three-point category instead: Table 7 shows Fleiss' Kappa values for stench, smell, cattle, and swine odors-where available, they are compared with Kappa values from the first measurement day of Sucker and Hangartner's study [14]. As can be derived from the table, our Kappa values are similar to those ones derived in the German study [14] when it comes to rating a stench or smell. However, the German study did not report values for specific odors, where panelist agreements generally seem rather low.

Table 7. Comparison of Fleiss' Kappa at seven- and three-categorical ratings.

\begin{tabular}{|c|c|c|c|c|}
\hline Odor & $\begin{array}{c}\text { Kappa (7-cat.), } \\
\text { Own Data }\end{array}$ & $\begin{array}{c}\text { Kappa (7-cat.) in } \\
\text { Sucker et al. c }\end{array}$ & $\begin{array}{c}\text { Kappa (3-cat.), } \\
\text { Own Data }\end{array}$ & $\begin{array}{l}\text { Kappa (3-cat.) in } \\
\text { Sucker et al. c }\end{array}$ \\
\hline Stench & $0.33^{a}$ & 0.39 & $0.70^{a}$ & 0.81 \\
\hline Smell & $0.29^{a}$ & 0.27 & $0.67^{a}$ & 0.70 \\
\hline Cattle & $0.08^{b}$ & - & $0.42^{b}$ & - \\
\hline Swine & $0.05^{b}$ & - & $0.24^{b}$ & - \\
\hline
\end{tabular}

\footnotetext{
Notes: ${ }^{\text {a }}$ data from 9 assessors. ${ }^{\mathrm{b}}$ data from 8 assessors. ${ }^{\mathrm{c}}$ data from the first of reported measurement days.
} 


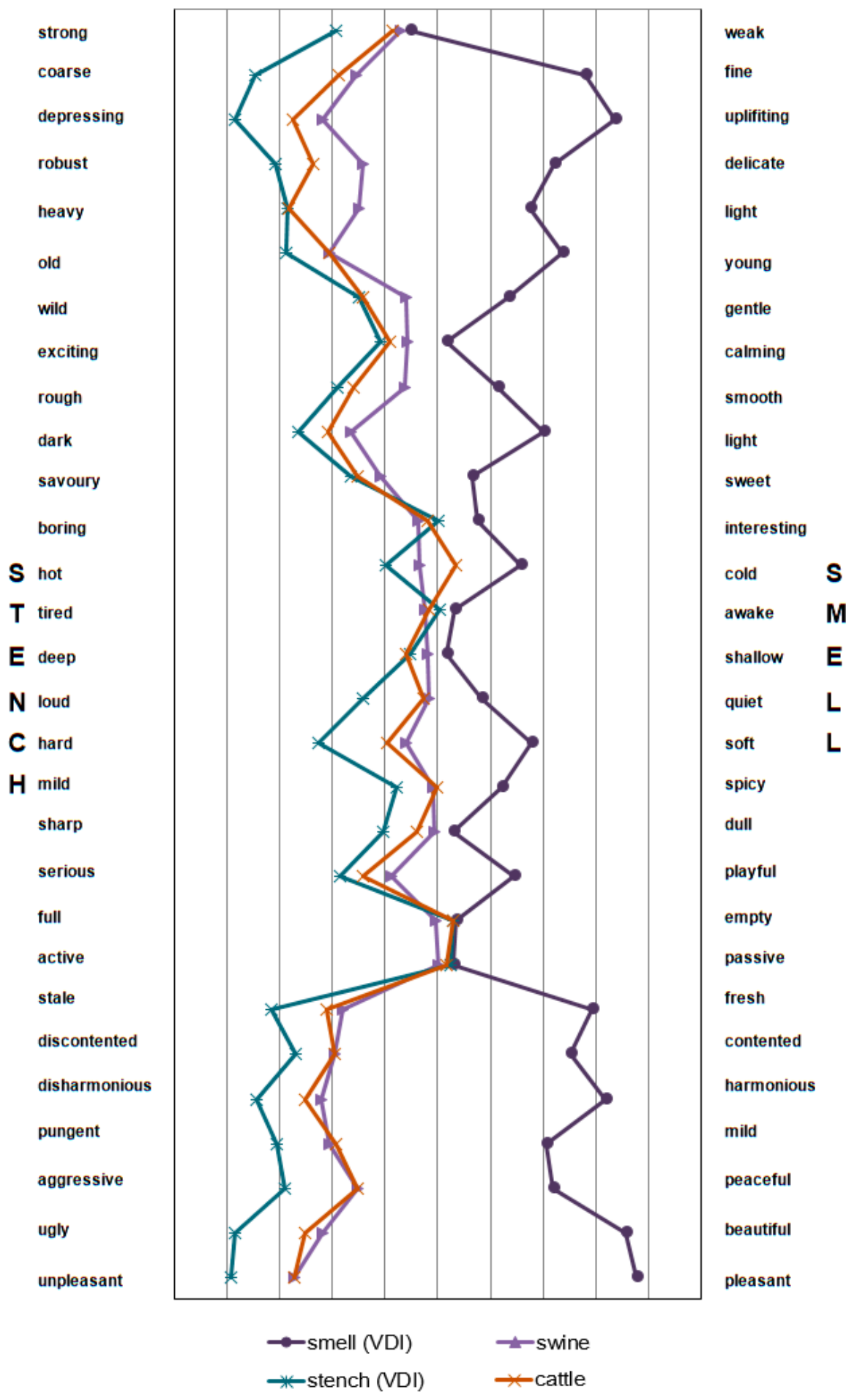

Figure 3. Polarity profiles [19] for the subjective ratings of cattle, swine, and representative stench and smell.

\section{Discussion}

Overall, our model including frequency and type of odors shows a better model fit than models just considering odor frequency or models based on the 98th percentile alone. Complaint rates in our data are comparable in magnitude to percentage of annoyed residents from the German study [6] and the Dutch study [10]. Our results are not completely comparable with the other studies, as those also considered personal health data as possible confounders. Personal health data of complainants were 
not available from our data set and would not be available in the administrative planning process of a new industrial plant or of a new stable. The Dutch study reported effect estimates for different models with different confounders. Effect estimates of odor intensity were not strongly influenced by the choice of confounders. Also, the German study demonstrated that most of the confounders considered did only have a small impact on annoyance and thus likely did not act as strong confounders. The Dutch and the German study did differ in their definition of annoyance and are therefore not fully comparable either. Generally, explained variance $\left(R^{2}\right.$ values) are modest in our models with exception for the extremely annoying odor of bowel cleanse (Table 3), but the underlying sample for the latter is very small. In particularly regarding swine farms, the explanatory power is low if the site is not considered (Table 4). However in general, the model fit for complaints is similar to that for annoyance in German and Dutch studies.

Generally, complaint rates for a given odor frequency were lower than in our previous study [5]. This is mostly due to the fact that in the new study we applied more realistic default emission rates. But it also reflects the fact that in our first study, only sites were included that triggered complaints, and complaints were probably overrepresented. In many parts of Austria, dispersion modeling is not mandatory in the planning process and it will only be performed when complaints are raised. Using administrative data to assess the association between odor frequency and complaint rates could in that case lead to somewhat biased results. In Styria for some time now dispersion modeling is mandatory in the planning phase and it is also a necessary requirement under the new Styrian guideline [12].

Needless to say, in authorization processes of farms and industrial plants, not only annoyance but even more strongly adverse health effects to neighbors must be prevented. Thus, if an odorous substance also has toxic, then properties emission control should be based on a toxicological risk assessment, not primarily based on an odor assessment. Toxic and odorous emissions do not necessarily go hand-in-hand: For example, an Italian study examining anaerobic digestions of cattle slurry showed that while digested slurry reduced odor emissions, ammonia emissions increased [32]. Hence, an assessment of both toxic and odorous emissions is necessary.

In our data, the individual site contributed substantially to the explanatory power of the regression model. A reason for this could be that calculated default emission values will not always be equally correct for every individual farm and when a farm's emissions are over- or underestimated, all surrounding neighbors are affected by that. We strongly recommend setting conservatively high default values and inviting the applicant to introduce odor reduction measures like specific feeding practices or waste removal schemes or filter techniques. New developments such as chemical scrubbers [33] for low-cost removals for $\mathrm{NO}_{X}$ and formaldehyde enlarge the pool of odor reduction techniques, and methods like the combination of non-thermal plasma adsorbers with mineral adsorbers show good removal rates for volatile organic compounds [34], but are currently not broadly used in Austrian stables. After providing evidence of the effectiveness of each measure (e.g., guarantee by the filter producer or third party gas analysis), emission factors could be adapted. That would act as an incentive to the introduction of such measures. But differences in complaint rates between stables are certainly also due to the social competence of the farmer, since personal relationships with farm owners could contribute to complaint rates from neighbors. But this factor cannot easily be assessed in a scientific study and also cannot be considered in the authorization process of a stable or any other source of odors.

Nevertheless, it can be shown that-in case complaint data are available-this data can be well-used for odor assessments in a regulatory setting. However, since types of odors differ greatly in causing complaints, this approach is applicable for odor sources where data already exists, but cannot be applied for new odor sources alone. The German guideline [10] does generally not differentiate between types of odors. Limit values for odor frequency are principally based on zoning plan categories with a limit value of $10 \%$ for housing areas. The German guideline only introduced certain weighting factors in the case of animal odors ( 1.5 for poultry, 0.75 for swine and 0.5 for cattle). When applying 
these weighting factors, the German guideline would permit about $17 \%$ for highly annoyed, $46 \%$ for annoyed (estimates based on Sucker et al. [6]), and for $24 \%$ complaining (own data) about poultry, as well as about $12 \%, 37 \%$, and $17 \%$ for swine and about $5 \%, 20 \%$, and (estimated) $0 \%$ for cattle.

In comparison, the Austrian guideline [12] defines four categories of odors based on their offensiveness and permits an odor frequency of $2 \%, 10 \%, 15 \%$, and $40 \%$ depending on the category. For each category only examples are provided. For the $40 \%$ category, cattle and horses are mentioned, for the $15 \%$ category swine and for the $10 \%$ category poultry. This would translate into about $23 \%$ highly annoyed and 33\% complaints for poultry, 13\% and 19\% for swine, and about $6 \%$ and (estimated) $0 \%$ for cattle.

To put these figures into perspective, it should be noted that for noise as another relevant environmental stressor, WHO Europe [35] suggests a permissible threshold of $10 \%$ highly annoyed people.

Regarding new odor sources, the method of polarity profiles seemed promising at first, but data do not support a very promising outcome. In the given form, the usability of the polarity profiles for rating new odors seems doubtful: First, regarding their connection to annoyance potency, polarity profiles for swine and cattle look nearly identical in our data (Figure 2), which differs from a German study [6] where cattle odors have also been reported to be less unpleasant than swine [6]. Also in our data - contrary to swine odors-no complaints about cattle odors were filed. A second flaw lies within the reliability of the method: The agreement in rating a representative stench or smell is sufficient and comparable with a German study [14], so the method seems to be valid overall when it comes to representative odors. Nevertheless, the agreement is insufficient when it comes to specific odors, with agreement for cattle $(\kappa=0.08)$ and swine $(\kappa=0.05)$ being basically non-existent on a 7-point-scale. Hence, on a seven-point rating scale, assessor agreements for specific odors do not seem sufficient to serve as improvement for existing guidelines. According with German results, a three-point-scale seems rather advisable (with $k=0.42$ for cattle and $k=0.24$ for swine), but would also need some improvement and generally contains the disadvantage that further sub-characterization disappears.

As an improvement for the polarity profiles, we suggest to also consider odor concentration. A French study [21] clearly showed the importance of odor concentration for annoyance potency, but so far the concentration has not been considered in the VDI 3940-4 guideline [19]. Also German studies [36,37] showed that intensity has an influence on the hedonic tone. Therefore, it seems possible that different concentrations could be a cause for the questionable validity and reliability of assessing specific odors. In our present data, the single polar of pleasantness did not discriminate between cattle and swine at all, so it is assumed that considering several polars might rather be helpful. But it should still be tested whether removing some non-discriminating polars might improve the model. Generally, the method of the polarity profile seems to need several adaptions before it can be applied for assessing the annoyance potency of new odor sources.

\section{Conclusions}

We have shown for some typical odors from animal husbandry that the percentage of complaining households and of (highly) annoyed persons are fairly comparable in magnitude and in statistical model performance. We have also shown that odor intensity which is used as an exposure metric in many countries and the odor units at the 98th percentile as used in the Netherlands in particular are comparable in predictive power to odor frequency as it is used in Austria and Germany. We have further demonstrated that polarity profiles as proposed by the VDI guideline [19] can distinguish between pleasant and unpleasant odors, but in their current form of application cannot discern between different grades of unpleasantness. The latter would be important to assess acceptable exposure for less well investigated odors. Since complaint rates are available from administrative registers, it should be easier to use these data than to generate annoyance data through new surveys. We propose utilizing this wealth of data, especially for less studied types of odor.

For regulatory purposes during planning processes, annoyance due to odors can be sufficiently well predicted based on odor frequency or intensity and type of odor. Complaint rates are often 
available in the administrative context and should be used to inform future policy. Complaint rates are a valid surrogate of annoyance and can therefore help defining relative offensiveness of still understudied odors.

An additional consideration of hedonic tone, assessed via polarity profiles, does not seem to be able to contribute in the present form due to reliability issues. Hence, it is suggested to investigate more thoroughly the influence of odor concentration also on the hedonic tone and on the performance of the polarity profile approach.

Author Contributions: Conceptualization, H.M.; dispersion model, D.O.; statistical analysis, H.M. and L.W.; investigation, D.O., M.M. and M.K.; writing —original draft preparation, H.M. and L.W.; writing—review and editing, H.M. and L.W.

Funding: This research received no external funding.

Conflicts of Interest: The authors declare no conflict of interest.

\section{References}

1. Freeman, T.; Cudmore, R. Review of Odour Management in New Zealand. Air Quality Technical Report No. 24. 2002. Available online: http://www.cschi.cz/odour/files/world/odour-tr-aug021.pdf (accessed on 17 August 2018).

2. Griffiths, K.D. Disentangling the frequency and intensity dimensions of nuisance odor, and implications for jurisdictional odor impact criteria. Atmos Environ. 2014, 90, 125-132. [CrossRef]

3. Nicell, J.A. Assessment and regulation of odor impacts. Atmos Environ. 2009, 43, 196-206. [CrossRef]

4. Brancher, M.; De Melo Lisboa, H. Odour Impact Assessment by Community Survey. Chem Eng Trans. 2014, 40, 139-144. [CrossRef]

5. Weitensfelder, L.; Moshammer, H.; Öttl, D.; Payer, I. Exposure-complaint relationships of various environmental odor sources in Styria, Austria. Environ. Sci Pollut. Res. Int. 2019, 26, 9806-9815. [CrossRef] [PubMed]

6. Sucker, K.; Müller, F; Both, R. Geruchsbeurteilung in der Landwirtschaft. Bericht zu Expositions-Wirkungsbeziehungen, Geruchshäufigkeit, Intensität, Hedonik und Polaritätenprofilen. Materialien 73; Landesumweltamt Nordrhein-Westfalen: Essen, Germany, 2006; ISSN 0947-5206.

7. Sucker, K.; Both, R.; Müller, F.; Winneke, G. Geruchsbeurteilung in der Landwirtschaft-Belästigungsbefragungen und Expositions-Wirkungsbeziehungen. VDI-Berichte Nr. 2007, 1995, 371-380.

8. Gallmann, E. Beurteilung von Geruchsimmissionen aus der Tierhaltung, Habilitation; Universität Hohenheim: Stuttgart, Germany, 2011; Available online: http://opus.uni-hohenheim.de/volltexte/2014/996/ (accessed on 18 September 2019).

9. Noordegraaf, D.; Bongers, M. Relatie Tussen Geurimmissie en Geurhinder in De Intensive Veehouderlij (Relation Between Odor Immission and Odor Nuisance for Intensive Livestock Farming); Rapportnummer VROM07A3; PRA Odournet BV: Amsterdam, The Netherlands, 2007.

10. Boers, D.; Geelen, L.; Erbrink, H.; Smit, L.A.; Heederik, D.; Hooiveld, M.; Yzermans, C.J.; Huijbregts, M.; Wouters, I.M. The relation between modeled odor exposure from livestock farming and odor annoyance among neighboring residents. Int. Arch. Occup. Environ. Health 2016, 89, 521-530. [CrossRef] [PubMed]

11. German GOAA. Detection and Assessment of Odour in Ambient Air. Guideline on Odour in Ambient Air-GOAA. 29 February 2008 with supplement of 10 September 2008. Available online: https://www.lanuv. nrw.de/fileadmin/lanuv/luft/gerueche/pdf/GOAA10Sept08.pdf (accessed on 18 September 2019).

12. Oettl, D.; Moshammer, H.; Mandl, M.; Weitensfelder, L. Richtlinie zur Beurteilung von Geruchsimmissionen, Bericht Nr: Lu-08-2018; Amt der Steiermärkischen Landesregierung: Graz, Austria, 2018.

13. Oettl, D.; Ferrero, E.; Moshammer, H.; Weitensfelder, L.; Kropsch, M.; Mandl, M. Recent Developments in Odour Modeling and Assessment in Styria and Salzburg, Austria. In Proceedings of the 19th International Conference on Harmonisation within Atmospheric Dispersion Modeling for Regulatory Purposes (Harmo 19), Bruges, Belgium, 3-6 June 2019.

14. Sucker, K.; Hangartner, M. Die Methode der Polaritätenprofile zur Beurteilung der hedonischen Geruchsqualität-Reliabilität und Validität. Gefahrst. Reinhalt Luft. 2012, 72, 411-417. 
15. Sucker, K.; Bischoff, M.; Krämer, U.; Kühner, D.; Winneke, G. Untersuchungen zur Auswirkung von Intensität und hedonischer Geruchsqualität auf Die Ausprägung der Geruchsbelästigung. Forschungsbericht. Medizinisches Institut für Umwelthygiene an der Heinrich-Heine Universität Düsseldorf (MIU) \& deBAKOM (Odenthal): 2003. Available online: https://www.lanuv.nrw.de/fileadmin/lanuv/luft/pdf/FB_Hed_Proj.pdf (accessed on 18 September 2019).

16. Osgood, C.E. The nature and measurement of meaning. Psychol. Bull. 1952, 49, 197-237. [CrossRef]

17. Dalton, P.; Maute, C.; Oshida, A.; Hikichi, S.; Izumi, Y. The Use of Semantic Differential Scaling to Define the Multi-Dimensional Representation of Odors. J. Sens. Stud. 2008, 23, 485-497. [CrossRef]

18. Seo, H.-S.; Lee, Y.; Yoon, N.-R.; Song, J.M.; Shin, J.-M.; Lee, S.-Y.; Hwang, I. Impacts of sensory attributes and emotional responses on the hedonic ratings of odors in dairy products. Appetite 2009, 53, 50-55. [CrossRef]

19. VDI 3940-4. Determination of the Hedonic Odor Tone-Polarity Profiles; Verein Deutscher Ingenieure: Düsseldorf, Germany, 2010.

20. Bayle, S.; Cadiere, A.; Cariou, S.; Despres, J.-F.; Fages, M.; Roig, B.; Sellier, A.; Fanlo, J.L.; Chaignaud, M. Odour Measurements at Different Methanisation Sites. Chem. Eng. Trans. 2018, 68, 79-84. [CrossRef]

21. Chaignaud, M.; Cariou, S.; Poette, J.; Fages, M.; Despres, J.-F.; Fanlo, J.-L. A New method to Evaluate Odour Annoyance Potential. Chem. Eng. Trans. 2014, 40, 13-18. [CrossRef]

22. VDI 3894-1. Emissions and Immissions from Animal Husbandry-Housing Systems and Emissions-Pigs, Cattle, Poultry, Horses; Verein Deutscher Ingenieure: Düsseldorf, Germany, 2011.

23. VDI 3940-1. Measurement of Odor Impact by Field Inspection-Measurement of the Impact Frequency of Recognizable Odors_Grid Measurement; Verein Deutscher Ingenieure: Düsseldorf, Germany, 2006.

24. Hayes, E.T.; Curran, T.P.; Dodd, V.A. Odour and ammonia emissions from intensive poultry units in Ireland. Bioresour. Technol. 2006, 97, 933-939. [CrossRef] [PubMed]

25. Mielcarek, P.; Rzeźnik, W. Odor Emission Factors from Livestock Production. Pol. J. Environ. Stud. 2015, 24, 27-35. [CrossRef]

26. Ogink, N.W.M.; Lens, P.N. Geuremissie uit de Veehouderij. In Overzichtsrapportage van geurmetingen in de Vakrenshoudrij, Pluimveehouderij en Rundveehouderij (Odour emissions from livestock operations); Institute for Agricultural and Environmental Engineering (IMAG-DLO): Wageningen, The Netherlands, 2001.

27. Oettl, D.; Kropsch, M.; Mandl, M. Odour assessment in the vicinity of a pig-fatting farm using field inspections (EN 16841-1) and dispersion modeling. Atmos. Environ. 2018, 181, 54-60. [CrossRef]

28. Zentner, E.; Mösenbacher-Molterer, I.; Huber, G.; Finotti, E.; Gasteiner, J.; Bachler, C.; Mayer, M.; Zainer, J.; Brettschuh, S.; Rudorfer, B.; et al. Investigation of a Feed Additive Regarding Emission Reduction and Performance with Consideration of the IED (IPPC) Guideline; Agricultural Research and Education Centre (AREC): Raumberg-Gumpenstein, Austria, 2012. Available online: https://www.raumberg-gumpenstein.at/cm4/de/ component/jdownloads/viewdownload/1762-3594-wt-delacon-ippc/13654-investigation-of-a-feed-additiveregarding-emission-reduction-and-performance-with-consideration-of-the-ied-ippc-guideline.html (accessed on 18 September 2019).

29. Oettl, D.; Kropsch, M.; Zentner, E.; Bachler, G.; Pollet, A. Geruchsemissionen aus Tierhaltungsanlagen (odor Emissions from Animal Husbandry), Bericht Nr.: Lu-06-2018; Amt der Steiermärkischen Landesregierung: Graz, Austria, 2018.

30. Oettl, D. Documentation of the Lagrangian Particle Model GRAL (Graz Lagrangian Model); Vs. 19.1.; Government of Styria: Graz, Austria, 2019.

31. EN 16841-1. Ambient Air-Determination of Odor in Ambient air by Using Field Inspection-Part. 1: Grid Method. Draft Version. 2017. Available online: https://www.en-standard.eu/din-en-16841-1-ambient-air-determination-of-odour-in-ambientair-by-using-field-inspection-part-1-grid-method/?gclid=CjwKCAjwo9rtBRAdEiwA_ WXcFmvMNDfhkgCxjWSz4NRQjldv4EPTWLXRkbrG4glao0aJPjM6fkeoshoCZQgQAvD_BwE (accessed on 26 October 2019).

32. Immovilli, A.; Fabbri, C.; Valli, L. Odour and ammonia emissions from cattle slurry treated with anaerobic digestion. Chem. Eng. Trans. 2008, 15, 247-254.

33. Dobslaw, D.; Engesser, K.-H.; Störk, H.; Gerl, T. Low-cost process for emission abatement of biogas internal combustion engines. J. Clean Prod. 2019, 227, 1079-1092. [CrossRef] 
34. Dobslaw, D.; Ortlinghaus, O.; Dobslaw, C. A combined process of non-thermal plasma and a low-cost mineral adsorber for VOC removal and odor abatement in emissions of organic waste treatment plants. J. Environ. Chem. Eng. 2018, 6, 2281-2289. [CrossRef]

35. WHO Europe. Environmental Noise Guidelines for the European Region; WHO Regional Office for Europe: Copenhagen, Denmark, 2018; ISBN 978-92-890-5356-3. Available online: http://www.euro.who. int/en/publications/abstracts/environmental-noise-guidelines-for-the-european-region-2018 (accessed on 19 September 2019).

36. Sucker, K.; Both, R.; Bischoff, M.; Guski, R.; Winneke, G. Odor frequency and odor annoyance. Part I: Assessment of frequency, intensity and hedonic tone of environmental odors in the field. Int. Arch. Occup. Environ. Health 2008, 81, 671-682. [CrossRef] [PubMed]

37. Sucker, K.; Both, R.; Bischoff, M.; Guski, R.; Krämer, U.; Winneke, G. Odor frequency and odor annoyance Part II: Dose-response associations and their modification by hedonic tone. Int. Arch. Occup. Environ. Health 2008, 81, 683-694. [CrossRef] [PubMed]

(C) 2019 by the authors. Licensee MDPI, Basel, Switzerland. This article is an open access article distributed under the terms and conditions of the Creative Commons Attribution (CC BY) license (http://creativecommons.org/licenses/by/4.0/). 